\title{
A qualitative analysis of women's explanations for changing contraception: the importance of non-contraceptive effects
}

\author{
Britta Wigginton, ${ }^{1}$ Melissa L Harris, ${ }^{2}$ Deborah Loxton, ${ }^{3}$ Jayne C Lucke ${ }^{4,5}$
}

For numbered affiliations see end of article.

\section{Correspondence to}

Dr Britta Wigginton, School of Medicine, The University of Queensland Centre for Clinical Research, Herston, QLD 4029,

Australia; b.

wigginton@uq.edu.au

Received 2 February 2015 Revised 2 November 2015 Accepted 30 December 2015 Published Online First

25 January 2016

\section{SLinked}

- http://dx.doi.org/10.1136/ jprhc-2016-101581

\section{CrossMark}

To cite: Wigginton $B$, Harris ML, Loxton D, et al.

$J$ Fam Plann Reprod Health Care 2016;42:256-262.

\begin{abstract}
Background Women commonly report changing contraceptive methods because of side-effects. However, there is a lack of literature that has thoroughly examined women's perspectives, including why they changed contraception.

Aim Using qualitative data from a contraceptive survey of young Australian women, we explored women's explanations for their recent changes in contraception.
\end{abstract}

Method A thematic analysis of 1051 responses to a question about why women recently changed contraception was conducted.

Results Themes reflected reasons for changing contraception which included: both contraceptive and non-contraceptive (4\%); relationship/sexual (9\%); medical (11\%); contraceptive (18\%); noncontraceptive (41\%). A minority of responses were uncoded (17\%). Non-contraceptive effects (effects unrelated to pregnancy prevention) featured most frequently in women's reasons for changing contraception.

\section{Conclusions While cessation of various} contraceptives due to unwanted side-effects is a well-known phenomenon, this analysis provides evidence of the changing of contraception for its non-contraceptive effects and reframes the notion of 'side-effects'.

Consistent use of effective contraception is important in preventing unplanned pregnancy. ${ }^{1}$ Factors contributing to contraceptive discontinuation or inconsistent use include issues accessing contraception $^{2}$ and method dissatisfaction. ${ }^{3}$ Side-effects are consistently cited as one of the most important factors influencing women's contraceptive (non-) use. $^{4-7}$

Side-effects are commonly viewed as unidirectional - that is, reports of side-

\section{Key message points}

- Side-effects continue to drive women's decisions to cease contraception, but this term is too narrow to allow a thorough understanding of women's decisions.

- 'Non-contraceptive' effects (effects unrelated to pregnancy prevention) frequently feature in women's decisions to change contraception.

- Clinicians may find it useful to spend time exploring why women request particular contraceptives, especially where other treatments might better meet desired non-contraceptive effects.

effects are shown to be linked to poor contraceptive use (e.g. using contraception outside of recommendations). For instance, multiple side-effects have been found to increase the likelihood of discontinuation. ${ }^{4}$ However, qualitative explorations on this topic are lacking. A recent literature review of evidence of women's contraceptive discontinuation concluded that aspects of women's voices are missing from clinical and epidemiological research, which has not adequately captured women's selfreported reasons for discontinuation, for instance, through the use of open-ended responses. ${ }^{8}$

We seek to situate women's contraceptive use and reports of side-effects within a social context, considering the influence of sociocultural factors, while at the same time acknowledging the embodied nature of contraceptive use. Taking a similar perspective, an analysis of 
interviews with 88 American women showed how side-effects were not experienced in a social vacuum, but rather the meanings attached to certain sideeffects were socially informed, reflective of a particular sociocultural context. ${ }^{9}$ Specifically, weight gain was viewed negatively by women and was likely to lead to discontinuation because 'women evaluate themselves against idealised beauty images that emphasise thinness' (p. 857). Additionally, an analysis of interviews with 72 Australian women described the importance of acknowledging the inherently contextual and transient meanings women attached to their decisions to use and change contraceptive methods. ${ }^{6}$ The authors concluded that it is impossible to identify one dominant or deciding factor influencing women's contraceptive decisions, and rather 'it is the interplay between competing influences of experience, relationships and fear of pregnancy' (p. 396).

In this article, we seek to problematise the tendency of previous studies to consolidate side-effects into a single category, rarely defining this category of effects, frequently with the implication that they are unwanted. The varied meanings women attach to these effects and how they relate to their contraceptive decisions are worthy of investigation. We propose that there is little information about how the effects of using contraception (both contraceptive and noncontraceptive) relate to women's contraceptive decisions. Using open-ended responses from an online contraceptive survey of young Australian women, this article asks, how do women explain their recent changes in contraception?

\section{METHODS}

CUPID (Contraceptive Use, Pregnancy Intention and Decisions) is a longitudinal population-based cohort study of young Australian women (aged 18-23) using three waves of online self-report surveys conducted at six-monthly intervals. The overarching aim of the CUPID project was to examine factors influencing contraceptive use and unplanned pregnancy among Australian women aged 18-23. Our survey examined: sociodemographics (e.g. work/study status); knowledge about, and attitudes to, contraception (e.g. feelings about the choice to use contraception); sexual and reproductive health histories (e.g. history of miscarriage; age at first sex); and health service use (e.g. doctor consultations; distance to health services). Most items were quantitative with some open-ended questions, allowing women the opportunity to elaborate upon earlier responses ('Please tell us more about...').

We recruited a cohort of 3795 women over a period of 12 months. Women were recruited through face-to-face events, social media, family planning clinics, media coverage, and word of mouth. This cohort was found to be largely representative of young Australian women in terms of demographic profile, with the exception of an over-representation of high school completers. ${ }^{10}$ The study received ethics approval from three university ethics boards and a local family planning clinic. The data reported here are from the baseline survey.

This article focuses on the survey question 'Have you changed, or started to use, contraception (protection) in the last 6 months'. Only women who responded 'yes' to this question were invited to elaborate in an open-ended text box ('Please specify why') - we focus on these data here. Responses to this question ranged from a few words to multiple sentences. Applying thematic analysis, ${ }^{11}$ the first author analysed the data with an interest in women's reasons for changing contraception. Thematic analysis is a common and flexible qualitative method for analysing text, allowing researchers to identify, analyse and report thematic patterns of data. We argue that an inductive thematic analysis fits within our question and our aim of bringing a women-centred understanding of contraceptive changes.

After a process of familiarisation, which involved reading and re-reading the data, the first author copied all data into Microsoft Excel and individually coded the data according to the reported reason/s for changing contraception. The high volume of responses allowed the first author to quickly develop a sense of the patterns across the data. Worksheets within Excel were created for coding each theme, allowing the first author to work closely within each worksheet to ensure consistency and coherence. Excel allowed the first author to effectively sort data (e.g. alphabetically) and track the number of responses within each worksheet.

The first author worked iteratively and inductively with the data until a set of five coherent and distinct themes that best reflected women's reasons for changing contraception had been developed. These included both contraceptive and non-contraceptive, relationship/sexual, medical, contraceptive, and noncontraceptive reasons for changing contraception. All responses are presented alongside participant ID numbers. A small portion of data $(n=177)$ were not coded because responses did not include a reason for changing contraception but rather described the change (e.g. 'Changed from pill to ring' \#850406; 'I stopped my pill' \#810603) or a contraceptive (e.g. 'Implanon' \#803827; 'Pill' \#846324).

A large proportion of women's explanations were related to non-contraceptive effects, which, following discussions with the other authors and data checking, we defined as effects related to using contraception that are unrelated to pregnancy prevention. We decided to focus on non-contraceptive effects in an effort to better understand the relevance of these effects in women's explanations for changing contraception, particularly because these effects were the most common and are the least well understood. This 
decision was driven by the dearth of existing research that has attempted to understand women's experiences of side-effects.

\section{RESULTS}

A total of 1094 women in our sample of 3795 indicated changing contraception in the last 6 months. Of these, 96\% $(n=1051)$ provided a text response to the question about why they had changed contraception in the last 6 months. Sociodemographic information for the women whose comments were analysed are shown in Table 1, and Table 2 shows their sexual and reproductive characteristics (both Tables include comparisons with the CUPID cohort).

We identified five themes depicting the key reasons for changing contraception; these are summarised in Table 3 alongside examples. Relationship/sexual reasons referred to a change in relationship status or sexual activity. Medical reasons related to a current medical condition, recent diagnosis, recommendations from doctors, medical information, or access to contraception (including requiring a prescription or waiting for a new contraceptive to be inserted). Contraceptive reasons oriented around pregnancy and included pregnancy prevention, fear of infertility, or a current or future pregnancy. Non-contraceptive

Table 1 Sociodemographic characteristics of women who commented on changing or starting contraception in the last 6 months compared with the full Contraceptive Use, Pregnancy Intention and Decisions (CUPID) cohort

\begin{tabular}{|c|c|c|}
\hline & $\begin{array}{l}\text { Study sample } \\
(N=1051)\end{array}$ & $\begin{array}{l}\text { Full CUPID cohort } \\
(N=3795)\end{array}$ \\
\hline Age (years) & $20.6 \pm 1.7$ & $20.7 \pm 1.7$ \\
\hline \multicolumn{3}{|l|}{ Highest education qualification } \\
\hline Less than year 12 & $112(10.7)$ & $345 \quad(9.1)$ \\
\hline Year 12 or above & $933(88.8)$ & $3365(88.7)$ \\
\hline Missing & $6(0.6)$ & 85 (2.2) \\
\hline \multicolumn{3}{|l|}{ Area of residence } \\
\hline Major city & $685(65.2)$ & 2415 (63.6) \\
\hline Inner regional & $216(20.6)$ & $824(21.7)$ \\
\hline Outer regional & $103 \quad(9.8)$ & 324 (8.5) \\
\hline Remote/very remote & $30 \quad(2.9)$ & $110(2.9)$ \\
\hline Missing & $17(1.6)$ & 122 (3.2) \\
\hline \multicolumn{3}{|l|}{ Relationship status } \\
\hline Married & $48 \quad(4.6)$ & $170 \quad(4.5)$ \\
\hline Separated/divorced/widowed & $4 \quad(0.4)$ & $15(0.4)$ \\
\hline Committed relationship* & $364(34.6)$ & $1220(32.1)$ \\
\hline Single & $628(59.8)$ & $2221(58.5)$ \\
\hline Missing & $7 \quad(0.7)$ & 169 (4.5) \\
\hline \multicolumn{3}{|l|}{ Employment status } \\
\hline In labour force & $706(67.2)$ & $2593(68.3)$ \\
\hline Not in labour force & $345(32.8)$ & $1131(29.8)$ \\
\hline Missing & $0(0.0)$ & 71 (1.9) \\
\hline
\end{tabular}

Values are mean \pm SD or $N(\%)$.

*Either living in a cohabitating relationship or engaged to be married.
Table 2 Basic sexual and reproductive health characteristics of women who commented on changing or starting contraception in the last 6 months compared with the full Contraceptive Use, Pregnancy Intention and Decisions (CUPID) cohort

\begin{tabular}{|c|c|c|}
\hline & $\begin{array}{l}\text { Study sample } \\
(N=1051)\end{array}$ & $\begin{array}{l}\text { Full CUPID } \\
\text { cohort } \\
(N=3795)\end{array}$ \\
\hline Age at first sex (years) & $16.5 \pm 1.9$ & $16.5 \pm 1.8$ \\
\hline Age at first pregnancy (years) & $18.6 \pm 2.2^{*}$ & $18.5 \pm 2.1 \dagger$ \\
\hline \multicolumn{3}{|l|}{ Contraception use (last 6 months) } \\
\hline $\begin{array}{l}\text { Hormonal contraception (e.g. the pill; } \\
\text { progesterone intrauterine device) }\end{array}$ & $253(24.1)$ & $967(25.5)$ \\
\hline $\begin{array}{l}\text { Non-hormonal contraception (e.g. } \\
\text { condoms; natural family planning; } \\
\text { withdrawal) }\end{array}$ & $69(6.6)$ & $390(10.3)$ \\
\hline $\begin{array}{l}\text { Combination of hormonal and } \\
\text { non-hormonal contraception }\end{array}$ & $717(68.2)$ & $1811(47.7)$ \\
\hline No contraception & $7 \quad(0.7)$ & $155(4.1)$ \\
\hline Missing & $5(0.5)$ & $472(12.4)$ \\
\hline \multicolumn{3}{|l|}{ Ever been pregnant } \\
\hline Yes/pregnant now & $259(24.6)$ & $716(18.9)$ \\
\hline No & $759(72.2)$ & $2524(66.5)$ \\
\hline I don't know & $22(2.1)$ & $66 \quad(1.7)$ \\
\hline Prefer not to answer & $7 \quad(0.7)$ & $25 \quad(0.7)$ \\
\hline Missing & $4 \quad(0.4)$ & $464(12.2)$ \\
\hline
\end{tabular}

Values are mean \pm SD or $N(\%)$.

* Denominator refers to women who reported ever being pregnant $(n=259)$.

tDenominator refers to women who reported ever being pregnant $(n=687)$.

reasons were any reasons unrelated to pregnancy prevention but still relevant to contraception.

We found that a substantial number of women $(n=428)$ described non-contraceptive effects as their reason for changing contraception. We identified two distinct ways of describing non-contraceptive effects: practical non-contraceptive effects and embodied noncontraceptive effects. A minority of women $(n=25)$ oriented to practical, non-contraceptive reasons for changing contraception. This referred specifically to the cost of a contraceptive (e.g. 'Could not afford to stay on the pill' \#846590 and 'the last pill was expensive' \#842991), which some described as becoming problematic in response to changes in living circumstances ('The pill that was fantastic for my skin is too expensive now that I have moved out of home' \#825776). We now explore embodied noncontraceptive effects.

\section{Embodied non-contraceptive effects: unwanted and wanted}

Women $(n=319)$ frequently described embodied experiences of non-contraceptive effects as a precursor to changing contraception. Overwhelmingly, these women $(n=258)$ described embodied, unwanted effects. These unwanted effects included: irregular, heavy or breakthrough bleeding; weight-, mood-, 
Table 3 Summary of themes* relating to reasons for changing contraception, across 1051 free text responsest

\begin{tabular}{|c|c|c|c|c|}
\hline $\begin{array}{l}\text { Both contraceptive and } \\
\text { non-contraceptive }(n=43)\end{array}$ & $\begin{array}{l}\text { Relationship or sexual } \\
(n=93)\end{array}$ & Medical $(n=117)$ & $\begin{array}{l}\text { Contraceptive } \\
(n=193)\end{array}$ & Non-contraceptive $(n=428)$ \\
\hline $\begin{array}{l}\text { Because I don't want babies just } \\
\text { yet, and the pill helps my acne } \\
\text { (\#834122) }\end{array}$ & $\begin{array}{l}\text { Became sexually active } \\
\text { (\#811448) }\end{array}$ & $\begin{array}{l}\text { Because I was } \\
\text { diagnosed with PCOS } \\
\text { and went on the pill } \\
\text { for it (\#830983) }\end{array}$ & $\begin{array}{l}\text { Am now off the pill as } \\
\text { I am scared of infertility } \\
\text { (\#827226) }\end{array}$ & $\begin{array}{l}\text { Because the Implanon made } \\
\text { me gain too much weight } \\
\text { (\#836071) }\end{array}$ \\
\hline $\begin{array}{l}\text { I have started the pill for both } \\
\text { contraceptive and painful periods } \\
\text { (\#884777) }\end{array}$ & First had sex (\#879448) & $\begin{array}{l}\text { Changed the brand of } \\
\text { pill I use due to } \\
\text { medical issues } \\
\text { (\#871198) }\end{array}$ & $\begin{array}{l}\text { After my abortion I } \\
\text { have decided to be } \\
\text { extra careful (\#847125) }\end{array}$ & $\begin{array}{l}\text { Changed due to heavier } \\
\text { periods, but acne got worse } \\
\text { so changed back (\#844168) }\end{array}$ \\
\hline $\begin{array}{l}\text { I tried the Mirena... it was terrible, I } \\
\text { am unreliable with my pill taking } \\
\text { and have problems with nausea } \\
\text { (\#828786) }\end{array}$ & $\begin{array}{l}\text { I had my first experience with } \\
\text { vaginal sex last year, and } \\
\text { since then I'm using condoms } \\
\text { as contraception as well as } \\
\text { the pill (\#847339) }\end{array}$ & $\begin{array}{l}\text { Doctor recommended } \\
\text { 30ED rather than 35ED } \\
\text { (\#809190) }\end{array}$ & $\begin{array}{l}\text { Changed from pill to } \\
\text { Implanon - would } \\
\text { often forget to take pill } \\
\text { (\#821740) }\end{array}$ & $\begin{array}{l}\text { I was on depo but was } \\
\text { experiencing loss of libido, } \\
\text { extreme mood swings and } \\
\text { depression (\#867340) }\end{array}$ \\
\hline $\begin{array}{l}\text { Period pain and pregnancy scare } \\
(\# 812346)\end{array}$ & $\begin{array}{l}\text { I started to have sex with my } \\
\text { boyfriend (\#851592) }\end{array}$ & $\begin{array}{l}\text { Doctors told me to } \\
\text { (\#868386) }\end{array}$ & $\begin{array}{l}\text { Condoms to prevent } \\
\text { pregnancy for now } \\
\text { (\#828518) }\end{array}$ & $\begin{array}{l}\text { The pill for my acne } \\
\text { (\#863702) }\end{array}$ \\
\hline $\begin{array}{l}\text { To get rid of acne and to have extra } \\
\text { protection (\#824027) }\end{array}$ & Male request (\#828810) & $\begin{array}{l}\text { I have stopped the pill. } \\
\text { Increases risk for } \\
\text { cancer (\#820615) }\end{array}$ & $\begin{array}{l}\text { Had a pregnancy scare } \\
(\# 888220)\end{array}$ & $\begin{array}{l}\text { Too many side-effects } \\
\text { (\#818264) }\end{array}$ \\
\hline $\begin{array}{l}\text { Used to have regular sex, and now } \\
\text { am not, also want to see what } \\
\text { stage my irregular bleeding is at } \\
\text { now that I'm off the pill (\#867996) }\end{array}$ & $\begin{array}{l}\text { Not having regular sex so } \\
\text { have stopped the pill } \\
\text { (\#859800) }\end{array}$ & $\begin{array}{l}\text { Implant removed and } \\
\text { not replaced as of yet } \\
\text { due to illness } \\
\text { (\#819937) }\end{array}$ & $\begin{array}{l}\text { I already have a baby } \\
\text { and don't want } \\
\text { another unplanned } \\
\text { pregnancy (\#843031) }\end{array}$ & $\begin{array}{l}\text { Had to change from regular } \\
\text { pill for cost reasons } \\
\text { (\#807889) }\end{array}$ \\
\hline $\begin{array}{l}\text { Started the copper IUD, due to } \\
\text { wanting an effective non-hormonal } \\
\text { method, but strongly disliking }\end{array}$ & $\begin{array}{l}\text { Stopped condom use with } \\
\text { primary partner (\#881210) }\end{array}$ & $\begin{array}{l}\text { Replacement of } \\
\text { Implanon due to expiry } \\
\text { (\#886079) }\end{array}$ & $\begin{array}{l}\text { I kept forgetting to } \\
\text { take the pill (\#883285) }\end{array}$ & $\begin{array}{l}\text { I have decided to go back on } \\
\text { the pill again after a } 6 \text { month } \\
\text { detox (\#856387) }\end{array}$ \\
\hline
\end{tabular}

condoms and not using them properly (responsibility of both me and my partner). Didn't want to keep using withdrawal method (\#877814)

Wasn't on the oral pill for a while as they were causing headaches but have started again so it is ready for when I get married in February. We don't want kids straight away as we are both going to be studying (\#887938)

Went from the pill to the copper IUD. Was forgetting to take the pill. IUD is cheaper and doesn't release hormones. The pill was giving me acne (\#863889)

Went off the pill due to weight gain/boyfriend moving away, started using condoms instead (\#886652)

\section{Use protection when not in a To manage relationship (\#816683) endometriosis (\#873670)}

\section{Was in a relationship and was on the pill and when this relationship ended I stopped using the pill and started using condoms with casual partners (\#882451) \\ Yes, just got into new relationship. No more Implanon. Trying pill (\#848244)}

\section{Contraceptive}

Am now off the pill as

I am scared of infertility (\#827226)

non made me gain too much weight have decided to be careful (\#847125) periods, but acne got worse

I was on depo but was $\begin{array}{ll}\text { often forget to take pill } & \text { extreme mood swings and } \\ \text { (\#821740) } & \text { depression (\#867340) }\end{array}$

Condoms to prevent pregnancy for now Had a pregnancy scare (\#888220)

Too many side-effects Had to change from regular pill for cost reasons and don't want

I kept forgetting to the pill again to go back on detox (\#856387)

\author{
I stopped taking the \\ pill because WE \\ wanted to have \\ another baby \\ (\#810621)
}

Trying to find a contraceptive pill that does not affect my depression as negatively (\#876536)

Taken off the pill by doctors due to heart conditions (\#853851)
Stopped taking the pill 6 months ago in order to conceive (\#856289)

Needed something more reliable than condoms (\#863370)
Stopped taking the pill to give my body a break from it (\#810988)

Previous contraception had not worked, by causing heavy bleeding (\#805801)

Trying to find the right pill for me (\#846599)

\footnotetext{
*Extracts are presented underneath each theme.

†The sample numbers represented in the columns do not add up to 1051 because 177 responses were not coded - see Methods for more detail. IUD, intrauterine device; PCOS, polycystic ovarian syndrome.
}

libido- and skin-related issues; and headaches or migraines - for example, 'Stopped taking The Pill as it made me very moody' (\#862651); and 'Changed from Implanon to Contraceptive Pill due to constant bleeding' (\#881154). Some women's responses merely described the effects: 'acne' (\#858643); and 'face, mood swings' (\#833525). Others did not report specific effects but rather described the sheer quantity of 'side-effects' as unmanageable, leading to changing contraception: 'Changed my pill, side-effects were bad' (\#872856); and 'Unfortunate side-effects' (\#813878).

Overall, a substantial number of women described embodied, unwanted non-contraceptive effects as a reason for changing contraception. This suggests to us that specific embodied experiences (weight gain, uncontrolled bleeding, acne, mood swings) indicate a lack of control over the body and hence require action. In particular, women prioritise their own embodied evidence in decision-making, in which 
these effects serve as legitimate evidence to prompt contraceptive changes.

It is important to note that women's experiences of non-contraceptive effects varied, in that they were not always unwanted, and they did not always lead to discontinuation. This is a salient finding in our analysis given the extensive literature linking 'side-effects' to discontinuation. We found that a minority of women $(n=61)$ described how they changed contraception for particular (desired) non-contraceptive effects. Women described changing contraception for menstrual suppression (and control), improved acne, preventing mood swings, and to help with existing medical issues (e.g. polycystic ovarian syndrome). The way in which women's responses were rhetorically structured suggested that their contraceptive change served a primarily non-contraceptive function: 'Changed pill for one better for my skin' (\#849774); 'The pill to regulate period for convenience' (\#854167); and 'Changed from pill to injection, helping to prevent mood swings' (\#874872). Some women cited multiple noncontraceptive benefits that they were seeking from their contraceptive:

Decided to start taking Yaz again for lighter periods (I've become anaemic in the past and needed transfusions) as well as to skip it because I get very bad menstrual migraines (\#835715)

We found that several women changed contraception to combat unwanted effects resulting from another contraceptive. This included either changing contraceptives (e.g. 'Implant was causing skin to flare up so went on Brenda pill, then moved to Dianette to help my skin more' \#880871) or adding a second contraceptive to achieve a particular noncontraceptive benefit (e.g. 'Briefly used the pill (1 month) to control breakthrough bleeding caused by Implanon implant' \#864988). In instances in which a secondary contraceptive was introduced for a noncontraceptive benefit, it was clear that the use of this secondary contraceptive was temporary.

We found that, in some instances when women spoke of changing contraception for desired non-contraceptive effects, these excluded any discussion of pregnancy prevention. However, there were some who did mention pregnancy prevention: 'Started the pill to deal with painful periods and to provide backup contraception' (\#809741). In this way, seeking non-contraceptive effects was combined with selecting contraception that also provided effective pregnancy prevention. For some women, non-contraceptive effects were not necessarily a primary reason for using contraception:

Changed to Implanon because I would forget to take my pills and wanted to be sure I was protected, also the possibility of no periods was very appealing (\#838735)

Looking closely at women's responses, we found that, in some instances, the language use suggested an acknowledgement that non-contraceptive benefits were not a certainty of using a particular contraceptive (e.g. 'try', 'possible', 'might'). This is notably distinct from accounts of unwanted, embodied non-contraceptive effects in which women commonly used language to indicate certainty about the effects that had prompted them to change contraception ('caused', 'due to', 'because of'). This suggests that non-contraceptive benefits may be viewed as more tentative (e.g. 'change pill type to try to limit period pains' \#805061) than unwanted, embodied non-contraceptive effects ('previous contraceptive pill caused weight gain' \#805625).

\section{Embodied non-contraceptive effects: a 'working' contraceptive}

Many women $(n=84)$ described changing contraception in response to perceptions of the 'right' contraceptive. This referred to the embodied experience of using contraception, the absence of negative noncontraceptive effects, and the perception of whether a contraceptive is 'right' for their body. For instance, women described being unable to find a contraceptive that was 'right for me' (\#833238) or 'one that suits' (\#839156). However, there was often little explanation of what made a contraceptive suitable or right for them, with a few exceptions: 'I'm looking for a contraceptive that suits me and causes the least sideeffects' (\#864637).

In addition, women described wanting to find a contraceptive that worked 'for my body' (\#818088). In these instances, there are references to an embodied sense of 'knowing' whether a contraceptive is working with or against their body - for example, 'Using contraceptive pill did not suit my body. Changed to condoms' (\#843002).

We also found that women described taking a 'break' or 'detox' from their contraceptive. Some women mentioned a break from hormones ('Stopped the pill 3 months ago don't want fake hormones in my body' \#888774), while others wanted a break from contraception to witness the effects this break has on their weight, menstruation, or moods ('Stopped taking pill as I have been on it for 8 years and wanted to see if I was now regular' \#810400). However, many women merely described taking a break, with little explanation of the purpose or reason for the break: 'Started using the pill again after a break' (\#851203). This suggests that a break from contraception may be a culturally shared term among young women.

\section{DISCUSSION}

This article examined women's explanations for changing contraception. While side-effects have received significant attention within contraceptive literature, cited as an important aspect of women's contraceptive use and experiences, ${ }^{4-6} 1213$ this literature (with a few exceptions ${ }^{5}{ }^{14}$ ) does little to describe women's perspectives of why and how side-effects are important. ${ }^{8}$ 
Our analysis indicated that women's explanations for changing contraception were overwhelmingly related to what we labelled non-contraceptive effects - that is, effects related to using contraception that are unrelated to pregnancy prevention. We identified two ways of describing non-contraceptive effects: practical noncontraceptive effects; and embodied non-contraceptive effects. Practical non-contraceptive effects related specifically to contraceptive cost. Embodied noncontraceptive effects were examined in more detail.

Overwhelmingly, women described embodied, unwanted non-contraceptive effects as the reason for changing contraception. This was often related to a specific effect or the quantity or the perceived seriousness of the effects. Unwanted effects included: irregular, heavy or breakthrough bleeding; weight-, mood-, libido- and skin-related issues; and headaches or migraines. Interestingly, libido is an effect that has been previously identified as important, ${ }^{15}$ but lacks empirical support. ${ }^{16} 17$

In addition, our analysis uniquely highlights that women change contraception for particular noncontraceptive benefits, including menstrual control, improved acne, preventing mood swings, and to help with existing medical issues. This finding challenges existing research that has typically paired 'side-effects' with discontinuation, with the assumption that such effects are unwanted. While previous qualitative research has found that women value contraception for menstrual control, ${ }^{14} 1819$ we know little about the extent to which embodied, wanted non-contraceptive effects motivate effective contraceptive use or decisions to use particular contraceptives. Further qualitative investigations would offer important implications for clinicians in better understanding women's motivations for effective contraceptive use in relation to non-contraceptive effects.

In a related way, we found that women's perceptions of the 'right' contraceptive prompted changing of their contraception. Although there was often little elaboration, beyond implicit references to an embodied 'knowing' of whether a contraceptive is 'right' for them, a similar way of discussing contraceptive use was identified in a previous analysis we conducted. ${ }^{20}$ In our view, embedded within the construct 'non-contraceptive effects' is the notion of control and, in particular, control over the female, reproductive body. ${ }^{21}$ Women's descriptions of managing embodied (unwanted and wanted) non-contraceptive effects orient to an attempt to gain control over the female body and experiences that are incongruent with idealised femininity ${ }^{9}$ (e.g. weight gain, uncontrolled bleeding, and acne).

Our analysis uniquely points to the importance of non-contraceptive effects in driving women's contraceptive changes. These findings, and our emphasis in defining non-contraceptive effects, is consistent with a recent conceptualisation of contraception as a 'lifestyle drug, ${ }^{22}$ in that contraception is no longer sold or valued solely on the basis of its efficacy for preventing pregnancy, but rather for its secondary benefits. In reflecting on the lack of attention to contraceptive effects in our data, we suggest that this may be because pregnancy prevention is now an assumed benefit of using contraception and so more attention is paid to non-contraceptive effects in their marketing as a 'lifestyle drug'.

Qualitative research can be useful in foregrounding the patients' perspective, which is useful for clinicians in terms of improving clinical outcomes. In particular, clinicians should be aware that non-contraceptive effects are common reasons for changing contraception. It is important for clinicians to have access to potential non-contraceptive effects associated with various contraceptives and to discuss these with women. This may help women identify potential unwanted (e.g. breakthrough bleeding) and wanted (e. g. improved skin) non-contraceptive effects and choose a contraceptive accordingly.

Owing to the structure of our survey, we were only able to explore women's reasons for changing contraception in the last 6 months. We were not able to examine why women were not changing contraception or sort responses according to patterns of change (i.e. starting, switching or stopping) or specific methods of contraception. In addition, it was impossible for us to follow-up or clarify women's responses with them. Rather, the value of using qualitative data was to provide an in-depth exploration of changing contraception from a large sample of young Australian women, without making generalisations to the broader population. These results lay the groundwork for future qualitative research (preferably interviews or focus groups), to examine non-contraceptive effects in more detail, or quantitative research, which would allow the extent of these issues in populations of women to be measured.

In the meantime, raising awareness among researchers and practitioners of the complex and transient nature of women's decisions with regard to contraceptive use, particularly in moving beyond the simple concept of (unwanted) 'side-effects' in this process, are important outcomes of this research.

\section{CONCLUSION}

While cessation of various contraceptives due to unwanted side-effects is a well-known phenomenon, the changing of contraception for its noncontraceptive effects (where in essence the contraceptive effect - pregnancy prevention - is a 'side-effect') is less well understood. We sought to examine women's reasons for changing contraception and in particular explore the prevalence of non-contraceptive effects. These effects can be both wanted and unwanted embodied non-contraceptive effects. It is important that clinical contraceptive consultations include space for young women to explain why they have chosen a particular contraceptive, particularly 
where the desired non-contraceptive effect might be better achieved with a different treatment.

\section{Author affiliations \\ ${ }^{1}$ Research Assistant, School of Medicine, The University of Queensland Centre for Clinical Research, Herston, Queensland, Australia ${ }^{2}$ Research Academic, Research Centre for Gender, Health and Ageing, Faculty of Health and Medicine, University of Newcastle, University Drive, Callaghan, New South Wales, Australia \\ ${ }^{3}$ Deputy Director, Research Centre for Gender, Health and Ageing, Faculty of Health and Medicine, University of Newcastle, University Drive, Callaghan, New South Wales, Australia \\ ${ }^{4}$ Director, Australian Research Centre in Sex, Health and Society, College of Science, Health and Engineering, La Trobe University, Melbourne, Victoria, Australia \\ ${ }^{5}$ Honorary Professor, University of Queensland Centre for Clinical Research, Herston, Queensland, Australia}

Twitter Follow Britta Wigginton at @brit_wig

Acknowledgements Thank you to all the women who kindly shared their experiences with us. This paper has not been previously presented, nor is it being considered for publication at another journal. Only the authors listed here were involved in the preparation of this manuscript.

Funding The research on which this paper is based was supported under the Australian Research Council's Linkage Projects funding scheme (Project Number LP100200349). We are grateful to the Australian Research Council and partner organisations, Family Planning NSW and Bayer Australia Ltd, for their financial support. There was no involvement from the financial partners in the preparation of this article, the analysis and interpretation of the data, the writing of the report or the decision to submit this article for publication.

Competing interests JCL is the Director of the Australian Research Centre in Sex, Health and Society at La Trobe University. She receives funding from the Australian Research Council and the National Health and Medical Research Council. She has served as a Director of Family Planning Queensland and been Chief Investigator on an ARC Linkage Grant that involves cash and in-kind support from Family Planning New South Wales and Bayer Australia. The Australian Research Centre in Sex, Health and Society receives funding from diverse sources listed in the annual report available from the website: http://www.latrobe.edu.au/arcshs

Ethics approval From two university ethics committees (University of Queensland and University of Newcastle) and the Family Planning New South Wales ethics committee.

Provenance and peer review Not commissioned; externally peer reviewed.

Data sharing statement Please contact the authors for access to unpublished data or research materials.

\section{REFERENCES}

1 Rosenberg MJ, Waugh MS, Long S. Unintended pregnancies and use, misuse and discontinuation of oral contraceptives. J Reprod Med 1995;40:355-360.

2 Westhoff CL, Heartwell S, Edwards S, et al. Oral contraceptive discontinuation: do side effects matter? Am J Obstet Gynecol 2007;196:412.e1-412.e7.
3 Moreau C, Cleland K, Trussell J. Contraceptive discontinuation attributed to method dissatisfaction in the United States. Contraception 2007;76:267-272.

4 Rosenberg MJ, Waugh MS, Meehan TE. Use and misuse of oral contraceptives: Risk indicators for poor pill taking and discontinuation. Contraception 1995;51:283-288.

5 Hoggart L, Louise Newton V, Dickson J. "I think it depends on the body, with mine it didn't work": explaining young women's contraceptive implant removal. Contraception 2013;88:636-640.

6 Mills A, Barclay L. None of them were satisfactory: women's experiences with contraception. Health Care Women Int 2006;27:379-398.

7 Dixon SC, Herbert DL, Loxton D, et al. 'As many options as there are, there are just not enough for me': Contraceptive use and barriers to access among Australian women. Eur J Contracept Reprod Health Care 2014;19:340-351.

8 Inoue K, Barratt A, Richters J. Does research into contraceptive method discontinuation address women's own reasons? A critical review. J Fam Plann Reprod Health Care 2015;41: 292-9.

9 Littlejohn KE. "It's those Pills that are Ruining Me": Gender and the Social Meanings of Hormonal Contraceptive Side Effects. Gender Soc 2013;27:843-863.

10 Harris ML, Loxton D, Wigginton B, et al. Recruiting online: lessons from a longitudinal survey of contraception and pregnancy intentions of young Australian Women. Am J Epidemiol 2015;181:737-746.

11 Braun V, Clarke V. Using thematic analysis in psychology. Qual Res Psychol 2006;3:77-101.

12 Bracher M, Santow G. Premature discontinuation of contraception in Australia. Fam Plan Perspect 1992;24:58-65.

13 McDaid LM, Buston KM, Mercer C, et al. "...the best of a bad bunch": a qualitative study of reasons for contraceptive discontinuation and switching among women in England. Contraception. In press.

14 Cheung E, Free C. Factors influencing young women's decision making regarding hormonal contraceptives: a qualitative study. Contraception 2005;71:426-431.

15 Sanders SA, Graham CA, Bass JL, et al. A prospective study of the effects of oral contraceptives on sexuality and well-being and their relationship to discontinuation. Contraception 2001;64:51-58.

16 Martin-Loeches M, Orti R, Monfort M, et al. A comparative analysis of the modification of sexual desire of users of oral hormonal contraceptives and intrauterine contraceptive devices. Eur J Contracept Reprodu Health Care 2003;8:129-134.

17 Schaffir J. Hormonal contraception and sexual desire: a critical review. J Sex Marital Ther 2006;32:305-314.

18 Gunson JS. "More natural but less normal”: reconsidering medicalisation and agency through women's accounts of menstrual suppression. Soc Sci Med 2010;71:1324-1331.

19 Brown KE, Arden MA, Hurst KM. A qualitative analysis of accounts of hormonal contraceptive use: experiences and beliefs of British adolescents. Eur J Contraception Reprodu Health Care 2007;12:269-278.

20 Wigginton B, Harris ML, Loxton D, et al. The feminisation of contraceptive use: Australian women's accounts of accessing contraception. Feminism Psychol 2015;25:178-198.

21 Ussher JM. Managing the Monstrous Feminine: Regulating the Reproductive Body. London: Routledge, 2006.

22 Watkins ES. How the pill became a lifestyle drug: the pharmaceutical industry and birth control in the United States since 1960. Am J Public Health 2012;102:1462-1472. 